\title{
Analysis of Traditional Media Marketing Path under the Impact of New Media
}

\author{
Ying Cheng \\ Changchun Sci-Tech University, Changchun, Jilin, 130600, China
}

Keywords: Traditional Media Marketing, New Media, Impact and Improvement

\begin{abstract}
With the continuous improvement of the level of science and technology, new media relative to traditional media has emerged and has been widely used. Traditional media and new media has rich forms. Although traditional media has certain advantages, there are also problems. In the new era, the competition between the two is increasingly fierce. Under the impact of new media, traditional media has achieved steady development. To adopt a positive marketing strategy, this paper studies the general situation of both new media and traditional media, and analyzes the marketing strategy, and expounds the application of traditional media marketing strategies in the context of new media.
\end{abstract}

\section{Introduction}

With the rapid development of the media industry, the industry actively uses advanced science and technology to provide technological support for the development of the media industry. At this stage, when traditional media develops, many of the challenges are mainly due to the pressure of new media. Under this circumstance, traditional media should actively use their own advantages while also using marketing strategies to ensure traditional media. Sustainable development.

\section{New media environment and features}

New media refers to the media forms that emerged in the context of the rapid development of new technologies, such as digital magazines, digital newspapers, digital broadcasting, mobile device terminals, mobile TV, networks, etc. The main technical resources used are digital technology, network technology, and satellite. Channels, etc. In the new media environment, the market scope has been expanded to a large extent, which has increased the consumption space of consumers. The new media environment also means that the international environment is included, providing more opportunities for the development of enterprises. In the traditional media era, enterprises have strong control over channels. Users usually play the role of listeners, and information presents a "one-way" communication model. In the new media era, because everyone has their own channels of communication, the information presents a complex "multi-directional" mode of communication. In the new media environment, the transmission of information and knowledge has the following characteristics: First, equality and interactivity. The new media has formed a multi-interactive form of communication between the media and the audience, and there is no need to identify each other's identity between the communicator and the recipient. Everyone is the communicator and recipient of the information, and the information is being realized. At the same time of two-way interaction, the equal communication between the two is realized. The second is timeliness and speed. New media technology breaks the time limit of traditional media. Anyone can receive the information they want, anytime, anywhere, and with the continuous upgrading of network communication technology, the information transmission is more timely and fast. On the Internet, people can spend Get the most effective information in the shortest amount of time. The third is openness and sharing. The new media not only breaks through the time limit, but also breaks through the geographical restrictions. No matter where the recipients are, the Internet can share information resources. Finally, the breadth of convergence and big data applications. "Internet +" has promoted the new format of media integration, helping traditional media to be dispersed from resources to resources, from superimposed to superimposed, from a single 
communication channel to a three-dimensional communication channel, and the market operation continues to expand the communication space and Channels have become an irresistible trend. Currently, the availability of data has increased. The massive, timely, dynamic and open data is conducive to improving the validity and depth of market operation analysis. Peng Tieyuan, secretary general of the National Big Data Professional Committee, stressed that big data is now infiltrating into every corner of the globe at a geometric growth rate. It is undeniable that big data brings new opportunities and challenges to new media communication. Market operations can fully utilize the characteristics, laws and trends of big data mining to better serve the enterprise market operations and enhance the core competitiveness of enterprises.

\section{Overview of new and traditional media}

New media is relative to traditional media, and its communication combines images, sounds and animations. New media actively use science and technology, such as network technology, computer technology and communication technology. Under the influence of technology, the forms of new media mainly include digital TV, computers and smart phones. New media has developed rapidly since its appearance and currently plays an important role in the media industry. The rapid development of new media is mainly due to its realization of the interactivity, timeliness and updateability of information transmission, and it has a rich communication channel. The new media has attracted a large number of young people. The scope of its audience is constantly expanding. Through the network, the audience of new media has realized the acquisition of information and the sharing of resources. At the same time, the new media is not limited by time and space, and it has become an important display. The window has realized the world's understanding and understanding of China. Not only is China's influence expanding, but China's comprehensive competitiveness has also increased. Under the new situation, the development of new media has the characteristics of marketization and industrialization, and meets the needs of market economy development. It takes traditional media as the basis for development and actively utilizes the advantages of traditional media. Through the effective combination of the two, it impacts The development of traditional media, through the competition of the two, its development is innovative and advanced.

Traditional media can also be called print media. Its mode of communication is more popular. The main role is to provide information, entertainment and culture to the people, mainly through the transmission of images and sounds through television, radio and newspapers. TVs have different channels, and the content of each channel is different. The categories of newspapers are mainly political, entertainment and people's livelihoods. Traditional media has a long development time and therefore has certain experience. Its advantages are mainly reflected in the following aspects: the content is powerful. Traditional media has great advantages in terms of content, mainly because of its richness and comprehensiveness. Communication is professional. Traditional media has a long development time, so it has accumulated a lot of experience and systematic knowledge in the work. The staff has a good comprehensive quality, and the work equipment is also advanced and professional. The impact is far-reaching. Through the brand effect, traditional media gradually improved its popularity. On this basis, its audience is relatively stable. At the same time, through the celebrity effect, the audience has expanded and promoted the development of traditional media. The shortcomings of traditional media mainly include unscientific systems and modes of communication, and their competitiveness is relatively weak. In traditional media, both television and newspapers have institutional problems, mainly in terms of personnel relations, medical insurance and income distribution. Due to the long development time of traditional media, it has more personnel and different qualities. The traditional media has more retirees, and its financial resources account for a larger proportion in medical insurance. In this case, new employees Low incomes have seriously affected the initiative of their work. The traditional media is affected by the planned economic system, and its employees' ideas are relatively old and backward, and cannot adapt well to the needs of market economy development. 


\section{Marketing strategies of traditional media in the context of new media}

In the context of new media, traditional media faces fierce competition and many challenges. It relies too much on advertising revenue. The singularity of the profit model directly affects the improvement of its comprehensive competitiveness. Therefore, in order to achieve sustainable development, traditional media Pay attention to the marketing strategy and combine different marketing strategies efficiently. Among them, special attention should be paid to product marketing. The products of traditional media are its content. The content plays a vital role in the development of the media. It can guarantee the growth of its economic benefits, and at the same time, content innovation can achieve the attraction of a wide audience. 3.1 The product strategy is at the current stage. Compared with the new media, the former market's market competitiveness is gradually declining, but it still has a broad base in the audience. Therefore, traditional media needs timely innovation to provide the audience with the needs. Service and content. Traditional media should attach great importance to product strategy and ensure the increasing number of audiences through innovative content. At the same time, in terms of management methods, profit models, program operations, etc., we must continuously optimize and adjust. The specific measures are as follows: (1) Word-of-mouth effect Traditional media must maintain a positive attitude and maintain a high degree of confidence in their own development through advertising. Gradually establish a brand image, and then expand the influence through the brand effect. With the continuous development of new media, some newspaper publications have been digitized, which has seriously affected the development of the news industry. At the same time, it has also caused a large number of employees to lose their jobs, mainly because the network has many advantages, such as convenience and speed. It's easier to get information. At present, when new media and traditional media develop together, the two must be effectively combined to gradually realize the sharing of information resources on the basis of satisfying customer needs. In the face of the impact of new media, traditional media must innovate, based on the needs of customers, to adjust the content, and to have full confidence in their own development, comprehensive analysis and research on customer needs, using their own Authoritative development of the market. When traditional media disseminates information, it must analyze the incidents and deal with the existing problems to realize the integration of resources. At the time of development, traditional media should pay attention to content and efficiency. At this time, the content should be targeted. According to the needs of the audience, the content should be selected. In the process of content dissemination, we should give full play to our own advantages and continue to innovate content and programs. , gradually form a representative and high-quality program, and ultimately achieve the continuous enhancement of traditional media influence. As an important channel for media revenue, new media has gradually integrated various advertisements in the development process. Under this circumstance, the audience gradually formed a rejection psychology. In the competitive environment, the advertisement of traditional media has a positive image. Its reputation is good, but new media lacks experience in the use of advertising.

In the market competition environment, traditional media must ensure the diversification and three-dimensionality of marketing methods in order to achieve steady development. Traditional media must change its own mode of communication. In order to achieve economic growth, all parts must cooperate to ensure the realization of marketing objectives through collaboration. Traditional media should learn from and learn from classic and successful marketing cases. Based on science and technology, traditional media should actively use advanced technology to gradually realize digital development. At the same time, traditional media must adhere to its own marketing model. Traditional media and new media are combined to meet the needs of the audience and increase their influence. In the process of development of traditional media, it is necessary to clearly recognize the change of audiences' access to information. At present, the audience is more willing to choose Weibo, WeChat, etc. to obtain information. Therefore, traditional media should learn from new media and gradually expand the traditional media. swipe. When traditional media has a broad audience base, advertisers naturally value the advertising investment of traditional media. 


\section{Conclusion}

Under the impact of new media, the development of traditional media has been severely challenged. In the face of tremendous pressure, traditional media should actively use marketing strategies, focus on product strategies, and combine other strategies to ensure the sustainability of traditional media.

\section{References}

[1] Gao Jingbo. Analysis of the Strategic Development of Educational Journals_—-Taking "Education Today" as a Case [J]. Journalism, 2008(6): 119-120.

[2] Chen Yuanshan. The construction of consumer information selection path in fragmented context [J]. National Business: Economic Theory Research, 2009 (18): 45-47.

[3] Li Li. Challenges and opportunities for the development of China's newspaper industry under the media integration environment [J]. Jin Media, 2010(1): 104-106.

[4] Gu Hong. The Evolution Path and Core Issues of China's Media Convergence Research from the Perspective of Industry_—A Summary of China's Media Industry Integration Research from 2005 to 2009[J]. International Journal of Press, 2010(3):100-107 .

[5] Jiang Jinjing. Reflections on the development of local brand industry-Taking Huaping Township, Jianshi County, Hubei Province as an example [J]. Science and Technology Entrepreneurship Monthly, 2011(3): 125-126. 